\title{
Challenging Cocacolisation of Rural Nepali Market: The Role of Education
}

\author{
Raj Kumar Dhungana ${ }^{1 *}$ and Alexandra Pfefferle ${ }^{2}$ \\ ${ }^{1}$ School of Education, Kathmandu University, Lalitpur, Nepal \\ ${ }^{2}$ Zürich, Switzerland
}

\begin{abstract}
The shelves of local shops are filled with an abundance of imported beverages. Coca-Cola, Pepsi, Fanta, Sprite, Frooti, and Red Bull among others have made the way to rural Nepal, where agriculture is still the primary source of income. As the result of increasing access to imported goods and products in rural markets, local products are gradually losing ground. This paper shows that tailored consumer education can assist de-cocacolising the market and increase the competitiveness and diversification of local products. It does so by imparting knowledge and skills to individuals to be critical and responsible consumers who start seeking an equal share of local products in the rural market. For this paper, extensive desk review, rural market observations and interviews with consumers of different age groups, vendors and youth wereused as data generation techniques.
\end{abstract}

Keywords: Cocacolisation, de-cocacolisation, consumer education, local products, postmodern consumer

\section{Diverse Consumers}

This paper starts with three brief stories of different types of consumers: traditional, modern and postmodern.

Story 1: We started to sell milk in our village 45 years ago and it has since become one of our major sources of income. At that time, milk was also a major 
32 R. K. Dhungana \& A. Pfefferle

part of our daily food. We used to consume fresh milk, yogurt, skimmed milk, butter and ghee every day. Over the time we had more and more cattle, mainly buffaloes and cows, and the milk production increased likewise. High in calories, ghee is the most nutritious food we have and it is essential for every religious and ritual activity in Hindu families. We still produce skimmed milk -the liquid remaining after spinning the milk to butter - every 15-20 days. This is less frequent than before. Our children don't like skimmed milk. They prefer fresh milk and yogurt. We haven't tasted Coke or Fanta in our entire life. It is impure and touched by people from lower castes. Even if somebody would offer it to us, we would not take it. We don't allow our children to drink imported drinks. Skimmed milk, in contrast, is very good for our health: it helps to increase our apatite; it gives us energy and stamina. We can work long hours with only drinking a mug of skimmed milk and it has no side effects. These days, you can see that this is changing slowly; younger generations are exposed to many new things and fashions, including imported beverages. (Interview with the Brahmin brothers Buda, age 69, and Tek, Age 64, in rural area of Kavre District, Nepal) ${ }^{1}$

Story 2: Sometimes, I drink Fanta but not every day. I like it because of its sweetness and fizziness. I would never give my children any money to buy Coke. I tell them to choose other drinks like Frooti ${ }^{2}$, yogurt and milk and they prefer those to imported beverages. I completed ten years of school. In the last ten years, I did not learn what is healthy to eat and drink. I know this from my parents and the elders in our community. What we eat, where and when we eat are often part of our beliefs and our daily practices. Nowadays, nobody buys skimmed milk in our local market. While milk and yogurt can be found in the local market, there is only one shop that sells yogurt. Coke, however, is found in many shops ${ }^{3}$. (Interview with Shiva, age 34, son of Tek, in rural area of Kavre District, Nepal)

Story 3: I like to drink skimmed milk and Coke. It depends on the place and time. In the market and with friends, I like to drink Coke and enjoy it, but when I am with my family and at home, skimmed milk is a better option. Personally, I prefer Fanta and Coke. My uncle says that Coke is bad for our health. I believe my uncle. I get NPR 10-15 per day to buy my daily snacks. This is not enough money for a bottle of Coke. Even if I had more money, I would not drink more than 3-4 small bottles of Fanta per month. It is a waste of money. With the same money I can buy better food. A $250 \mathrm{ml}$ Coke costs NPR 30 and the same amount of fresh milk only costs NPR 20, so why should I go for Coke?(Interview with Rabin, age 16, son of Shiva, in rural area of Kavre District, Nepal)

Journal of Education and Research | March 2016, Joint Issue 5.2 \& 6.1 


\section{Introduction}

The three stories of these people reflect the complexity of the Nepali rural market. Their voices, representing three different generations of a traditional Nepali rural family, have something in common: they are all, in some way, exposed to a fast changing rural market and a process of cocacolisation. Yet, their responses to this change are quite different. Cocacolisation, as used in this paper, is a process of domination of globalised products like Coke, Fanta and Pepsi over the local products like skimmed milk and fresh milk.

Since the introduction of globalised products in Nepali market in 1984, traditional products have gradually disappeared from Nepal's rural market and have almost been replaced by such globalised products like Coca-Cola, Fanta, Sprite, Pepsi. The complexity of the Nepali rural market originates from the various interests and behaviours of its traditional, modern and postmodern consumers as well as from globalised products that have penetrated the local markets. A large number of Nepali rural people believe that such globalised drinks are impure and harmful. Consequently, they do not drink such beverages. Yet, the use of local drinks, like fresh milk, skimmed milk and sarbat (mixture of lemon, sugar and water), has decreased in Nepal and gradually been replaced by globalised drinks. The consumption of Coke and similar beverages is slowly becoming part of local peoples' regular life.

In rural Nepal, where agriculture is still the primary source of income, the rising consumption of globalised goods is of major concern, because of its cultural and economic impacts. Consumers in developing countries often prefer brands from abroad, for example, the U.S. or Germany, over brands that are seen as local in origin. By choosing these products they seek to demonstrate higher social status and a lifestyle similar to those in economically developed regions (Batra et al., 2000; Howes, 1996, as cited in Nagata, Barg, Veleggia, \& Bream, 2011).

Today, $77 \%$ of Nepali are living in rural areas. This is far above the global average (Central Bureau of Statistics [CBS], 2011). In our observations of Nepal's rural areas, shops are filled with an abundance of different imported products and many young consumers tend to prefer foreign brands. The postmodern consumers believe that their identity is associated with what they use or consume (Berner \& Tonder, 2003). The consumer behaviour of the young Nepali shows certain characteristics of a postmodern consumer - a consumer that not only chooses a product because of its necessity or taste but also because it provides him or her with a desired identity (Peltonen, 2013). By consuming 
34 R. K. Dhungana \& A. Pfefferle

global products, they feel prestigious and proud. Their selection of certain products is largely determined by aggressive advertisements of multinationals that have recently appeared in the rural market; peer consumer behaviour; and the purchasing capacity of the consumer.

Although general access to education and information in Nepal has increased, rural consumers and vendors lack access to reliable information about local and global products and short and long term impacts of those products on their socioeconomic life. Moreover, these consumers have very little understanding of how and to what extent they can influence the economy, the environment and the society through their individual behaviour.

Through the lens of postmodernism, using a critical approach, this paper analyses the modalities of cocacolising Nepal's rural market versus a decocacolised Swiss rural market and explores how consumer education can influence the share of local products in Nepal's rural market while contributing to an equitable co-existence of global and local products. Case studies, market observations, interviews and focused group discussions were carried out in June 2014 in Kavre, Kathmandu and Kailali District's rural markets in Nepal, whereas interviews and market observations were conducted in Switzerland in September 2014. This paper explored the ways education can enable local products re-gain an equal share in the local market.

\section{Cocacolisation in Rural Nepal}

Nepali rural market is neither totally traditional nor postmodern in nature. The three stories are representatives of the diverse and complex Nepali rural consumers. Similar to these stories, Kabita, a newly married, 19 years old girl of a rural family, mentioned, "I like to drink Coke and imported beverages. I drink it two-three times a month but if I had more money, I would drink more." Her 42years old mother-in-law added that she drinks Coke only a few times in a year when she travels to her mother's house. Kabita's 84-years old grandma never tasted Coke or any other imported beverages in her entire life. These statements confirm the stories presented at the beginning of this paper and portray a Nepali rural market that is neither totally traditional nor postmodern in nature. Many young people get exposed to a wide range of global products through extensive travel that they undertake in their search for employment. They have started to believe that global products would be better than the local ones. Kabita's husband, who is just back on leave from Saudi Arabia, trusts foreign products more than local ones, because they are, according to him, of good and trustworthy brands. 
The phenomenon of domination of the rural market by global products has been frequently referred to as cocacolisation (Nagata et al., 2011) and is seen as one of the many instruments and means of globalisation. Globalisation refers to increase the flow of cross-border movement of goods, services and capital, increased human movement and increased market diversification (Hillebrand, 2010). Some interpret cocacolisation as a product of modernism and globalisation, while others refer it as a form of Americanisation and westernisation. Koestler (1976) even takes it a step further and coined the term 'coca-colonisation' to describe the impact of Western societies on developing countries and the results of Western intrusion into the lives of traditional-living indigenous communities (as cited in Zimmet, 2000). We are here using the term cocacolisation and with it Coke as a symbol for the availability of globalised products in the local market which are gradually displacing local market products.

Marketing strategies of multinational companies entering new markets often tend to be aggressive. Mainly targeting teens and children, they aim to create demand by changing traditional habits and reproducing necessities, so that global products are becoming an obvious choice for the rural youth (Mariola, 2005). The consumer in postmodern culture is perplexed by the incredible array of brands and products that impose their own rules and procedures as a way of life. The well-packaged products advertise a high western lifestyle where consumers enjoy their consumption and identify themselves with the product. Postmodernist studies argue that consumers seek to express themselves and their relationships to others through the products as they symbolise their identity (Elliott \& Wattanasuwan, 1998). Identity construction thus plays an important role in the way consumers perceive themselves (Firat, 1991). The consumers transcend the state of just satisfying their individual needs, and become positioned and identified by what they consumes.

Buda and Tek, Shiva, and Rabin's stories give us an example of the Nepali rural consumers' mindset and symbolise three different types of consumers: the traditional, modern and postmodern. Buda and Tek, two traditional consumers, seem to be reluctant to new products, calling them impure and culturally inappropriate. They are satisfied with traditional local products.

Shiva, a modern consumer, explores new products and is informed. He is ready to negotiate the price and conscious about different brands, and packaging. For Shiva, consumption is not only to fulfill his needs but also to acquire prestige and identity. 
Rabin, the third character represents a postmodern consumer. He cares not only about price and branding but is also emotionally attached to his favourite brands. The unpredictability is one of the major characteristics of postmodern consumer (Featherstone, 2007).

These individuals representing three generations are not exclusively fixed to one type of consumer as their behaviour may differ in different contexts and cultures. Together they reflect the complexity of the market.

The local market - Haatbazar ${ }^{4}$ in Nepal - was originally created as a space for exchanging local products but has since converted into a place to sell imported goods. Apart from vegetables, a majority of goods and products in the local Haatbazar are imported. In the Haatbazar in Kailali, about 150 shops are lined up along both sides of the main road. Whether it is a city centre's market or the Haatbazar, globalised products, like bottled drinks and packaged fast food, and local products, mainly grains and fresh vegetables, are kept together. Ram Chaudhary, one of the many local shopkeepers, said, "Twenty years ago there was no practice to have these kinds of shops, but now you can see them everywhere." With the extension of the road and a better connection to town, the number of outlets exploded and imported beverages became dominant in the market within only 10 to 15 years. While most of the shops sell imported beverages, there is only one that sells yogurt, yet none of them sells skimmed milk in Kushadevi, Kavre. There are a number of negative effects of regular use of fast food and globalized beverages. Zimmet (2000) argued that the use of Coke and fast food caused a diabetes epidemic which is also the most obvious disease in developing countries.

At the beginning of 2000, there were 130,000 market outlets in rural Nepal (Subedi, 2002). In the last 15 years, the number of market outlets has significantly increased. Globalised products have gained a dominant space in these markets and the number of local shopkeepers selling imported beverages has also significantly increased. Incentives such as free refrigerators and high profits, promised by re-sellers of global products, contributed to this trend. Similarly, self-employed and without any formal training, local sellers seem not to be concerned about the consumers' changing habits. Bharat, a local seller of Jaharsingh Pauwa, Kathmandu, for instance stated: "We sell what consumers buy, what wholesalers sell and from which we get more profit." In rural areas, compared to urban markets, the demand for imported products is rather low. "The market for these new products is not very large-people do not have sufficient cash to purchase imported beverages", explained Dhaniram of Kailali District. As a low-income 
country with a GNI per capita of USD 730 (World Bank, 2013) the purchase of a bottle of coke paying NPR 25, remains for many beyond their means. Even though a bottle of Coke in Nepal is more than 10 times cheaper than in any Western country, one could with the same amount of money buy a small meal in Nepal.

Nepal took important steps for the liberalisation of its economic policies under the Structural Adjustment Programme (SAP) initiated in 1986 (Khan, 2000), but major reforms for integration into the global economy came only in the early 1990s. Until then, people in rural areas used to share their products free of cost with their neighbours. Today Nepal's rural market is still largely agro-based. Most of the Nepali farmers produce for their own consumption and the little surplus is sold in the rural markets. The traditional barter system and the culture of sharing are gradually disappearing, as the local level buyers started purchasing those little surpluses, including milk and milk products (mainly ghee, yogurt and fresh milk), fresh fruits and vegetables, grains, and cereals. Presented in attractive wrapping and of different exotic tastes, imported beverages are tempting the new rural generation.

Multinational companies use seductive schemes to advertise their products, targeting in particular children and teenagers. Drinking Coke makes you feel happy, Win a ticket to the World Cup in Brazil, Win one KG Gold and Win an apartment in Kathmandu are some of the recent slogans used by the Coca-Cola Company in Nepal. Young actors, popular singers, and famous sportsmen are paid to convey these slogans getting millions of rural consumers motivated to pay NPR 25 for a bottle of Coke. Contrarily, local products like fresh milk, skimmed milk and yogurt are far behind in marketing. Furthermore, consumers do not have access to all the information about the consequences of using local and globalised products. Therefore, local drinks do not have the same attraction and are, in many cases, not even available, or only on request, in local stores.

"I would drink Red Bull everyday if I had the money to buy it. Because it is tasty, gives a good feeling and makes us smart”, said Binod, a 15 year old boy that we met in a rural school in Kathmandu District. For him, Red Bull not only tastes good, it also provides him with a desired identity by making him feel good and smart. "Red Bull is popular among our youth because it also contains some portion of alcohol and it is accepted as non-alcoholic beverage among parents", adds Bharat who operates one of the tiny shops. This clearly indicates that it is not only the lack of information, but misinformation that leads to the consumption of imported beverages. 
"We are what we eat" is a famous axiom. Nepali rural people largely eat self-grown, self-cooked, meat and vegetables. Eating habits, clothing and cultural practices construct the identity of rural people. Nepali Hindus believe that local products, which are accepted socially and culturally, are suitable for them. Referring to the Hindu text, a Hindu scholar Chintamani Yogi argues that local food is far better than the imported one. He encourages people to consume Satwik Bhojan which is generally local, homemade, self-cooked and very simple food, to be a vegetarian and to avoid alcohol. Rajashi Bhojan is another category of food that, according to the Hindu tradition, is suitable for warriors and royal family. It consists of 84 food items, including different spices, meat, and sweets. A third type of food is Tamashik. It is said that this third type is particularly good for manual workers as it is extremely nutritious. The belief 'we are what we eat' is inherited from generation to generation through daily food practices, learning from elders and the exposure to religious texts. Recent developments of Nepal's rural market tend to hamper this process, breaking with the knowledge chain that has been in place for centuries.

Besides Nepal's traditional knowledge, food habits are also determined by the access to food. Rural people have significantly reduced their consumption of skimmed milk because of two reasons. First, they started to sell fresh milk directly to the market, before processing it to skimmed milk. Selling milk and milk products to local dairy shops has become one of the major sources of income for rural people. These shops then process the milk and sell the milk products to outlets in the region. Second, with the migration of many rural farmers to urban areas and other countries for employment, including other than agro-based activities, the milk production has gone down. A large number of youths are absent in their villages as they are working aboard or in urban centers.

Today, $45 \%$ of Nepal's population aged 15-24 is working abroad or in the capital (CBS, 2011) and remittances contribute to $25 \%$ of Nepal's GDP (World Bank, 2013), which is in an increasing trend. Rural families have now access to cash, which they can use to purchase imported goods and products. Increased access of cash has lowered the barrier, in particular for adolescents, to consume fast food from the local market. The Millennium Development Goals Progress Report 2013 shows that Nepal made significant progress on education, health and poverty reduction (United Nations Development Program, 2013). As a result general consumers are becoming more aware of the different products. Consumers' awareness is increasing; they like to know more about the quality and use of products (Aryal, Chaudhary, Pandit, \& Sharma, 2009). Yet, consumer 
education is a very new area of discourse in Nepal. Today, consumer education that informs children about available products still needs to become part of the school curriculum. Rajesh Paudyal, principal, of a Secondary School of Kavre District seemed concerned about the consumption of junk food among his students: "They prefer to eat roasted and dry noodles over local food like roasted maize." He advises children not to use junk food and encourages them to eat homemade food items. Rajesh gets the information about the products from newspapers, local health workers and uses his common sense to guide children in what is best for their health. He also acknowledges that teachers themselves are not informed about the consequences of using packed, readymade foods and beverages. He mentioned, "We are not trained about it, rather we have learnt informally by listening to others.” (Personal Communication, June 14, 2014).

In 1998, under the Consumer Protection Act 1998 a Consumer Protection Council was established in Nepal. The Council is mandated to inform consumers about the products and to protect their rights. Article six ensures the right to consumer education. While this law is very appealing, the reality shows a different picture. In general, consumers are not informed about their rights and vendors are not concerned about it. Bharat, who owns a small shop in rural Kathmandu, mentioned that he does not look at the expiration date while buying and selling products, because he is just not used to do so.

It is observed that the rural markets have become places where low quality products are promoted and rural communities generally trust the sellers about the product quality including nutritional value, manufacture date, price, and brands of the new products. Participants in our focus group discussions confirmed that generally they do not care about the quality and manufacturer while buying imported products. Most of the respondents also affirmed that they never thought about the consequences of using imported products.

\section{Understanding De-Cocacolisation}

Rabin, our youngest interviewee, would ask, "So why Coke?" or "Why not Coke?" His grandmother would ask, "Why not skimmed milk?" These questions reflect the complexity of the Nepali rural society, where the younger generation shows some of the characteristics of a postmodern consumer that sharply contradicts with their older generations. Media and modern communications have been effectively used to prove Rabin as rational and his grandmother's advice to 
40 R. K. Dhungana \& A. Pfefferle

drink skimmed milk as an irrational and out-dated idea and have so contributed to the decline of traditional knowledge. Yet, would it be possible to de-cocacolise or de-globalise Nepal's society, especially, when it is steadily moving towards modernity and post-modernity?

In the postmodern market, it is difficult to predict why consumers choose what they choose. Hamouda and Gharbi (2013) presented that the consumers are not primarily looking to impress others but they are seeking to live deeply in themselves in all different identities which they built. If consumers are seeking to live in themselves, why should we even bother to think for de-cocacolisation as they are sovereign consumers? Stiglitz and Charlton (2006), among others, argue that trade liberalisation in poor countries with badly performing market structures may cause unemployment and decline productivity. Consumers are free to choose what they want, but whether their choice is well-informed or not is a major concern.

Besides the new and enormous range of globalised products available in the market, other factors have played an important role in enduring their presence. Better infrastructures, labour migration to urban areas and foreign countries as well as the selling of raw materials to bigger distributers have facilitated the penetration of imported products. De-cocacolisation, used as the breaking with the domination of imported goods, seeks to create a space for local products in the market. The processes of cocacolisation and de-cocacolisation, however, have to be understood as complementary rather than mutually exclusive. This contributes to the dietary transition where consumers are able to make a conscious choice between local and global products.

Consumer education for the young rural postmodern consumers can be used as one of the vehicles of the de-cocacolisation process. We have seen that the process of cocacolisation is both constructed by modernity and supported by postmodern consumers who make themselves part of the new dominating culture through their choices and preferences. Likewise, well-informed and dynamic postmodern consumers, acting as individuals or groups, have the power to challenge this dominant reality, supporting a de-cocacolisation process.

Increasing the share of local products in the market needs a very deliberate effort of consumers, vendors, and distributers, multinationals as well as government officials. Education can play a very crucial role in this process by informing the different actors about the value of the products as well as raising their awareness on the power of consumer's behaviour. In order to do so, 
education both formal and non-formal needs to be re-designed. Starting with the dissemination of information about newly available as well as traditional products, education needs to go from the classical to a postmodern and transformative approach. Appropriate consumer education promotes critical thinking and respect for diversity, and fosters dialogue at different levels: traditional and modern; local and global producers; wholesalers and retailers.

In an interview with Vice President of Coca-Cola Company in India Mr. Neeraj Garg spoke mentioned that:

Nepal is a country which has a relatively low per capita consumption levels for packaged beverages and we see steady and robust growth in both sparkling and still beverage categories in the future. The per capita consumption of our products is only 9.2drinks per year, which is far less than in Mexico with 728 and China with 38 drinks per person per year. (Lamsal, 2013)

The Coca Cola Company clearly sees a window of opportunity to sell more beverages in the Nepali rural market, which in their view has not yet been sufficiently exploited. Low income and high transportation cost to remote hilly areas are some of the major reasons for the low per capita Coke consumption in Nepal. This, however, also presents the perfect time to start consumer education and to inform about imported, packaged, preserved foods. As the Nepali market is not fully globalised, consumer education could prevent cocacolisation by increasing people's knowledge of modern and local products in a way that they can make their own informed choices.

There is not a simple way to de-cocacolise minds and markets. Education has been used as a vehicle of cocacolisation and can be used the same way for a de-cocalisation process. Learning from Swiss experiences, Nepal can create a new approach of de-cocalisation that creates a constructive dialogue between the producers of global and local products and educates consumers and investorsto create a just market where both local drinks, like skimmed milk, and Coke can coexist so that consumers have more choices.

\section{Swiss Experience of De-Cocacolisation}

In Switzerland, consumers are well informed about the quality and origin of the available goods and can select from a wide range of local products. Due to a very high proportion of small and middle sized companies, distributers' support of rural products, favourable national policies and an increasing consumer demand 
42 R. K. Dhungana \& A. Pfefferle

for products that are locally produced, marketed and consumed, local products are getting better positioned. Over the last three decades, the Swiss agricultural sector has gradually decreased. In 2012, 162,000 people worked in agriculture, less than half as many as in 1975. More than half of them worked part-time. The number of farms has also fallen continuously, only between 2000 and 2012 from 70,500 to 56,000 . However, over the last 20 years, $60 \%$ of the Swiss food consumption could be covered by domestic production (Federal Statistical Office [FSO], 2014).

Progressive policy reforms to support the agricultural sector were made in Switzerland in the late 1990s targeting subsidies towards ecological practices (Swiss Agency for Environment, Forests and Landscape, 1999). The public support was in particular given for specific biotypes, integrated production and organic farming. Policy now differentiates between three different levels of public support depending on the sustainability of agriculture. Tier one is support for specific biotypes, such as extensive grassland and meadows, high-stem fruit trees and hedges. Tier two supports integrated production with reduced inputs, meeting higher ecological standards than conventional farming. Tier three is support for organic farming (Swiss Agency for Environment, Forests and Landscape, 1999). A vital element of the policy process was also that responsibility to set, administer and monitor is delegated to cantons, farmers' unions and farm advisors, local bodies and non-government organizations. Most of the farmers are able to comply with the basic ecological standard which allows them to receive public subsidies.

In 2012, the Swiss Confederation spent CHF 3.7 billion on the agricultural and food sectors. Of this amount, $78 \%$ was paid as direct payments and social contributions to the entitled farmers (FSO, 2014).

Over the years Swiss consumers have paid more attention to the quality and origin of the products that end up in their shopping baskets. Today's Swiss consumers appreciate local products and are ready to pay an extra price for it, if convinced. This has been taken so far that today's consumer is able to trace back the way of his boiled morning egg. Consumer education has played a crucial role in informing consumers about the different products and has supported them in making their everyday decisions in a way that supports local farmers. For this, local government published and distributed information materials among rural consumers and also introduced lessons on nutritional science and consumer behaviour in schools.

Swiss small and middle sized vendors and distributers adapted their marketing strategies to the nature of the postmodern consumer, fostering the 
latter's identification with the product and letting the consumer become part of a bigger movement towards more sustainable local markets. Supermarkets have created separate sections where they have only products that come from the region in which the particular supermarket is located. The products are usually well labeled so that the consumers could easily find the producer and consumers can ask for more information if they want. Small local stores selling typical local products have also gained popularity. These local food items are often quite expensive. It is the uniqueness and localness the costumers appreciate and which gives them the feeling of supporting their community. They are thus also willing to pay a higher price for it. With a higher income, households in Switzerland spent roughly only $12 \%$ of their budget on food (FSO, 2014).

Beside all the range of different products, Coke is still a popular drink among Swiss people. With the consumer's changing lifestyle, Coca Cola has also adapted its marketing strategy to the new type of consumer and focuses on the needs and well-being of its consumers reducing the caloric value by more than $10 \%$ over the past 7 years. The company supports numerous sporting events and promotes a healthy, active lifestyle. Further, Coca Cola dealers respect the responsibility of parents. As a result, the company does not advertise its products to children below the age of 12. Classrooms are ad-free zones and absolutely no promotions are conducted in schools. Vending machines are only installed at the expressed wish of the school's administration. The Swiss example demonstrates that to increase the share and diversification of local products in the rural market it is essential to disseminate information about their values and to increase people's identity with local products.

\section{Role of Education on De-Cocacolisation}

Article 6 of the Consumer Protection Act (Ministry of Law and Justice, 1998) mentioned that Nepali people are entitled to the rights to consumer education. This provision is further elaborated in the Consumer Protection Regulation (Ministry of Law and Justice, 2000), which states that the consumer education shall be included in the curriculum of schools and colleges to educate consumers about the type of goods and services to be consumed and to make consumers aware of the adverse effects of consuming substandard goods. This law ensures that all types of consumers are entitled to receive adequate information and education about the global as well as local market products. In addition to the Consumer Protection Act 1998 and Regulation1999, Nepal has also other legal provisions that not only protect consumers' rights to education but also protect local products. The 
44 R. K. Dhungana \& A. Pfefferle

Competition Promotion and Market Protection Act 2007 outlines that Nepal will enhance national productivity through the development of business capacity of producers or distributors by way of competition and by protecting markets against undesirable interferences (Ministry of Law and Justice, 2008).

These policies indicate that education can play a vital role in promoting local markets by informing students and community about their rights and duties as consumers. Yet, neither teachers nor the students of Nepali schools are found informed about these policies. In addition, these policies remain one of the many yet to be implemented policies in Nepal (Poudel, 2007).

Chintamani Yogi, an educationist and a noted spiritual leader in Nepal, mentioned that there is no reliable information available about the consequences of junk food in Nepal (Interview, 14 May, 2014). In addition, lack of adequate policies and poor policy enforcement has provided an open space for big international companies to push their products into rural communities often through aggressive marketing strategies.

Globalised product sellers like Coca Cola companies are strategically moving in the rural market. In an interview, Neeraj Garg, Vice President at Coca Cola India and South West Asia stated:

With regards to the beverage industry in Nepal, I think the packaged beverage consumption is on the rise and the non-alcoholic ready to drink category continues to evolve to varying consumer demands. Coca Cola has a strong focus on innovation and we will continue to provide our consumers with beverage choices for all occasions and cater to the advancements of the Nepali beverage market. (Lamsal, 2013)

The Swiss case shows that consumer education can assist de-cocacolising the market and increase the competitiveness and diversification of local products. It is important to inform consumers about the value and quality of available imported and local products as well as their socio-economic impacts on society. It would not only allow consumers to understand the process of cocacolisation but also reflect on the role they can play to strengthen local economy. By imparting knowledge and skills to individuals, education can empower them to make their contribution to an equal share of local products in the rural market.

Consumer education in Nepal has to address some of the misconceptions created by the cocacolised market. Drinking Coke means being modern and 
smart is one of the major misconceptions we observed in the Nepali market. To educate postmodern consumers, we need to adjust, accommodate and cope with the changing dynamics of local as well as globalized products. Berner and Tonder (2003) discussed doubt, ambiguity and uncertainty as major characteristics of postmodern consumers. And, our education system should work with unpredictable learners - the learners who make their own choice and decide what they choose to learn so that consumers are aware of their rights and responsibilities. In order to challenge this understanding, consumers, in particular young consumers, need to re-awake their appreciation for local products that have been produced over many centuries and are still deeply enshrined in their traditions. For young consumers, these products need to be presented attractively and they need to be informed about their benefits in comparison to the imported, packaged and readymade food products. As a result, using local products should make them feel proud. Exposed to a wide array of different products, consumers need to choose again local products because they feel proud of consuming such products and because such local products provide them with a desired identity. By investing in local production and knowledge about local products, and its transfer from generation to generation, education can increase newer generations' understanding for traditional food items as well as their identification with it as being part of a culture.

Access to information about local as well as global products is not only important for consumers, but also for vendors, teachers, curricula developers, and business leaders. Whether it is local or global, (post)modern consumers should be able to make informed choices, and not just partially informed or misinformed choices. The Swiss rural market experience provides us with a case how a holistic understanding of the functioning of the market can empower consumers to make their own choices in the local market. Similarly, it will let them become part of a bigger movement towards a more sustainable local market. In addition, building up skills and investing in local infrastructure can contribute to the promotion of local products beyond the borders of their market and create a demand from post-modern consumers all over the world which in turn will contribute to an increase in their value at the local level. The global business houses need to be encouraged to invest part of their profit to promote local products. Mechanisms and institutions need to be established that make sure that a certain percentage of the profit is re-invested to produce and market local products. With a better infrastructure, increased access to roads, higher income through remittances 
46 R. K. Dhungana \& A. Pfefferle

and the selling of surpluses, the Nepali rural market has high potential to grow and promote its products. Well-informed consumers and distributers can act in a sensitive and responsive way, allowing local products equal space in the local market.

\section{Conclusion}

Nepali rural markets are increasingly dominated by imported goods. This domination of imported products over local ones has created both opportunities as well as challenges in Nepal's rural society. The influence of imported goods on consumers drives them to buy imported goods and products like Coke. In turn, local products, like skimmed milk, that have a higher nutritious value are ignored. Importantly, long term social and economic dimensions of cocacolisation have yet to be part of education system in Nepal since the consumers there are either partially informed or misinformed. The Swiss example shows that effective consumer education and awareness, increased investment in local quality products, distributers' support for rural products, special space for local products in supermarkets and favourable national policies can equalise the prestige of local products to the global imported ones.

\section{Notes}

1 The informants names have been changed to maintain confidentiality.

2 Frooti is a packaged drink available in different brands in Nepal. It contains high sugar and additives with fruit flavour and said to be the largest-selling mango flavoured drink in India.

3 The local market in Kusadevi consists of about 150 shops and Coke is available in one third of the shops in the market.

4 Haatbazar is a temporary market established in rural centers where local people bring their small amount of products and sell, and exchange their goods and products. Generally, they come together once or twice a week.

5 Some 5000 farms (8 percent) are now organic (up from two percent in 1991), and most farmers are now expected to meet the 'ecological standard' during the year 2000. Pesticide applications have fallen by 23 percent since 1990, and phosphate use is down from 83 to $73 \mathrm{~kg} / \mathrm{ha}$ (FSO, 2014).

\section{References}


Aryal, K. P., Chaudhary, P., Pandit, S., \& Sharma, G. (2009). Consumer's willingness to pay for organic products: A case from Kathmandu valley. The Journal of Agriculture and Environment, 10, 12-22.

Berner, A., \& Tonder, C. V. (2003). The postmodern consumer: Implications of changing consumer expectations for organization development in service organizations. Journal of Industrial Psychology, 29(3), 1-10.

Central Bureau of Statistics. (2011). Nepal population and housing census, 2011. Kathmandu, Nepal: Author.

Elliott, R., \& Wattanasuwan, K. (1998). Brands as symbolic resource for the construction of identity. International Journal of Advertising, 17(2), 131-144.

Featherstone, M. (2007). Consumer culture and postmodernism. London, England: Sage.

Firat, A. F. (1991). The consumer in postmodernity. In R. H. Holman \& M. R. Solomon (Eds.), Advances in consumer research (Vol. 18, pp. 70-76). Provo, UT: Association for Consumer Research. Retrieved from: http://www. acrwebsite.org/search/view-conference-proceedings.aspx?Id=7141

Federal Statistical Office. (2014). Swiss agriculture pocket statistics 2014. Retrieved from http://issuu.com/sfso/docs/1112-1400

Hamouda, M., \& Gharbi, A. (2013). The postmodern consumer: An identity constructor. International Journal of Marketing Studies, 5(2), 41-49.

Hillebrand, E.E. (2010). Deglobalization scenarios: Who wins? Who loses? Global Economy Journal, 10(2). doi: 10.2202/1524-5861.1611

Khan, A. R. (2000).Globalization and sustainable human development: An assessment of challenges facing Nepal. Kathmandu, Nepal: UNCTAD/UNDP.

Lamsal, M. (2013). Coca-Cola strives be relevant to new generations. Retrieved from http://www.newbusinessage.com/Interview/1059

Mariola, M. J. (2005). Losing ground: Farmland preservation, economic utilitarianism, and the erosion of the agrarian ideal. Agriculture and Human Values, 22, 209-223. doi:10.1007/s10460-004-8281-1

Ministry of Law and Justice. (1998, January 28). Consumer protection act 1998. Nepal Rajapatra, 47(54).

Ministry of Law and Justice. (2000). Consumer protection regulation, 1999. Kathmandu, Nepal: Author. 
48 R. K. Dhungana \& A. Pfefferle

Ministry of Law and Justice. (2008).Competition promotion and market protection act 2007. Kathmandu, Nepal: Author.

Nagata, J. M., Barg, F. K., Veleggia, C. R., \& Bream, K. D. W. (2011). CocaColonization and hybridization of dietsamong the Tz'utujil Maya. Ecology of Food and Nutrition, 50, 297-318.

Peltonen, J. (2013). Behave yourself - Identity power of consumption: A contemporary view. Retrieved from https://aaltodoc.aalto.fi/bitstream/ handle/123456789/12634/ hse_ethesis_13506.pdf?sequence=1

Poudel, K. K. (2007). Understanding provisions of consumer's protection in Nepal. Kathmandu, Nepal: European Commission - Nepal, WTO Assistance Programme.

Stiglitz, J. E., \& Charlton, A. (2006). Aid for trade: A report for the Commonwealth Secretariat. Retrieved from http://unctad.org/sections/ditc tncdb/docs/ditc_tncd_bpgeneva03-06_en.pdf

Subedi, N. (2002, December 20). Rural consumers. Nepali Times. Retrieved from http://nepalitimes.com/news.php?id=4488

Swiss Agency for Environment, Forests and Landscape (1999). Swiss agricultural policy: Objectives, tools and prospects. Retrieved from https://www.cbd.int/ financial/pes/swiss-pesagriculturalpolicy.pdf

United Nations Development Program. (2013). Nepal millennium development goals progress report. Kathmandu, Nepal: Author.

World Bank. (2013). Migrants from developing countries to send home $\$ 414$ billion in earnings in 2013. Retrieved from http://www.worldbank.org/en/ news/feature/2013/10/02/Migrants-from-developing-countries-to-send-home414-billion-in-earnings-in-2013

Zimmet, P. (2000). Globalization, coca-colonization and the chronic disease epidemic: Can the doomsday scenario be averted? Journal of Internal Medicine, 247, 301-310. 